\title{
Reproductive history and risk of colorectal adenocarcinoma in parous women: a Nordic population-based case-control study
}

Tone Bjørge ${ }^{*}, 1,2$, Mika Gissler ${ }^{3}$, Anne Gulbech Ording ${ }^{4}$, Anders Engeland ${ }^{1,5}$, Ingrid Glimelius $s^{6,7}$, Maarit Leinonen $^{8}$, Henrik Toft Sørensen ${ }^{4}$, Steinar Tretli ${ }^{2}$, Anders Ekbom ${ }^{6}$, Rebecca Troisi ${ }^{9,10}$ and Tom Grotmol ${ }^{2,10}$

${ }^{1}$ Department of Global Public Health and Primary Care, University of Bergen, Bergen, Norway; ${ }^{2}$ Cancer Registry of Norway, Oslo, Norway; ${ }^{3}$ National Institute for Health and Welfare (THL), Helsinki, Finland; ${ }^{4}$ Department of Clinical Epidemiology, Aarhus University Hospital, Aarhus, Denmark; ${ }^{5}$ Department of Pharmacoepidemiology, Division of Mental and Physical Health, Norwegian Institute of Public Health, Bergen/Oslo, Norway; ${ }^{6}$ Department of Medicine, Clinical Epidemiology Unit, Karolinska Institutet and Karolinska University Hospital, Stockholm, Sweden; ${ }^{7}$ Department of Immunology, Genetics and Pathology, Uppsala University, Uppsala, Sweden; ${ }^{8}$ Cancer Society of Finland, Finnish Cancer Registry, Helsinki, Finland and ${ }^{9}$ Division of Cancer Epidemiology and Genetics, National Cancer Institute, National Institutes of Health, Department of Health and Human Services, Bethesda, MD, USA

Background: Data are conflicting regarding the role of endogenous sex hormones in colorectal carcinogenesis. In this large population-based study, we pooled data from birth and cancer registries in four Nordic countries, to evaluate the risk of colorectal adenocarcinoma in relation to women's reproductive history.

Methods: We conducted a population-based case-control study among women registered in Nordic birth registries. The study included colorectal adenocarcinoma cases diagnosed in Denmark, Finland, Norway, and Sweden during 1967-2013 and up to 10 matched controls per case, in total 22185 cases and 220246 controls. Odds ratios (ORs) with 95\% confidence intervals (95\% Cls) were derived from conditional logistic regression models. We had limited information available on possible confounders.

Results: We found no evidence for associations between colorectal adenocarcinoma and parity, age at first and last birth, and time since first and last birth. The risk estimates were also close to unity for specific cancer subsites (proximal and distal colon and rectum). As well, when the analyses were stratified on menopausal status, parity, and mother's year of birth, no indication of associations was found.

Conclusions: In this large, Nordic population-based study, no evidence for associations was found between women's reproductive history and colorectal adenocarcinoma in parous women.

Colorectal cancer is the second most common cancer in women worldwide (GLOBOCAN 2012), and $\sim 55 \%$ of the cases occur in more developed regions. In the Nordic countries during 2010-2014, the cumulative risk of disease before age 75 was $4.1 \%$ in males and 3.2\% in females (NORDCAN) (Engholm et al, 2010). Median age at diagnosis was 69 years in males and 71 years in females. The female incidence rate was highest in Norway
(36.2 per 100000 person-years) and lowest in Finland (20.6 per 100000 person-years).

Most cases of colorectal cancer are sporadic, and develop over many years through the adenoma-carcinoma sequence (Brenner et al, 2014). A family history of colorectal cancer (Taylor et al, 2010), inflammatory bowel disease (Ullman and Itzkowitz, 2011; Jess et al, 2012), smoking (Liang et al, 2009), high alcohol

*Correspondence: Professor T Bjørge; E-mail: Tone.Bjorge@uib.no

${ }^{10}$ These authors contributed equally to this work.

Received 1 May 2016; revised 19 August 2016; accepted 6 September 2016; published online 4 October 2016

(c) 2016 Cancer Research UK. All rights reserved 0007-0920/16

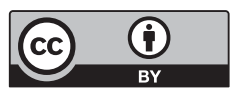


consumption (Fedirko et al, 2011), high consumption of red and processed meat (Bouvard et al, 2015), obesity (Ma et al, 2013), and diabetes (Larsson et al, 2005) are established risk factors, while physical activity (Boyle et al, 2012), aspirin/nonsteroidal antiinflammatory drug (NSAID) use (Friis et al, 2015; Drew et al, 2016), and endoscopic screening, with removal of precancerous lesions (Elmunzer et al, 2012), have a protective effect.

As men have higher lifetime risk of colorectal cancer than women, it has been speculated that oestrogen might have a role in decreasing risk, at least partly mediated by oestrogen receptor (ER)-beta, the predominant ER subtype in the human colon (Campbell-Thompson et al, 2001). As opposed to the subtype ER-alpha's growth-promoting properties, ER-beta exerts an antiproliferative effect on non-transformed colonocytes (Zhao et al, 2010). A protective effect of oestrogens may also be mediated through lower serum levels of insulin-like growth factor-I (Campagnoli et al, 2003; Renehan et al, 2004) and decreases in secondary bile acid production (McMichael and Potter, 1980; Bayerdorffer et al, 1995). Colorectal cancer subsites, which have been reported to vary by sex (Iacopetta, 2002; Lee et al, 2015), exhibit differences in pathogenesis, genetic and epigenetic alterations, and molecular pathways (Lee et al, 2015).

Strong evidence that exogenous hormones have a role in colorectal carcinogenesis derives from observational studies and clinical trials, which demonstrate an inverse relation between postmenopausal hormone therapy (HT) use and risk of colorectal cancer (Grodstein et al, 1999; Chlebowski et al, 2004; Lin et al, 2012). A meta-analysis, summarising results from cohort as well as case-control studies, also reported a $20 \%$ reduction in colorectal cancer risk among ever-users of oral contraceptives (OCs) compared with never-users (Bosetti et al, 2009).

At the same time, epidemiologic data have been conflicting regarding the role of endogenous sex hormones in colorectal carcinogenesis. A US study on the role of reproductive history and risk of colorectal cancer found positive associations between age at menopause and age at first childbirth and colorectal cancer risk in postmenopausal women, whereas age at menarche and parity were inversely associated with risk (Zervoudakis et al, 2011). However, a recent Swedish study found that higher parity was associated with increased risk of adenocarcinoma of the proximal colon ( $\mathrm{Lu}$ et al, 2014). In contrast, a study from the European Prospective Investigation into Cancer and Nutrition found no association between reproductive history and colorectal cancer risk (Tsilidis et al, 2010). A 2013 meta-analysis also found no association between age at menarche and risk of colorectal cancer (Li et al, 2013).

In our large population-based study, pooling data from birth and cancer registries in four Nordic countries, we aimed to evaluate the overall risk of colorectal adenocarcinoma, as well as risk by cancer subsites, in relation to women's reproductive history (parity, age at first and last birth, and time since first and last birth), being a surrogate measure of her lifetime exposure to endogenous sex steroids or other biomarkers related to reproductive events.

\section{MATERIALS AND METHODS}

Data sources. This study was based on data collected from nationwide population-based registries in the four Nordic countries. Nordic birth registries contain information on all births in Denmark, Finland, Norway, and Sweden since 1973, 1987, 1967, and 1973, respectively (Gissler et al, 1997). Reporting of cancer cases is compulsory in the Nordic countries, and the cancer registries of Denmark, Finland, Norway, and Sweden cover the entire national populations since 1943, 1952, 1953, and 1958, respectively (Engholm et al, 2010). All residents of the four Nordic countries are assigned a unique country-specific personal identification number, which is used in all registries and makes accurate record linkage possible.

Study design. The data were analysed within a case-control design, including all colorectal adenocarcinoma cases diagnosed in Denmark (1973-2011; $n=4680)$, Finland (1987-2012; $n=923)$, Norway (1967-2013; $n=9797)$, and Sweden (1974-2013; $n=6785$ ) among women registered with a prior pregnancy (lasting longer than 22 weeks) in the birth registries. The rationale for including only parous women was to create a study group as homogenous as possible with respect to fertility. We included only the first cancer (any cancer) for each case. Up to 10 controls per case were sampled among women in the birth registries with a prior pregnancy lasting longer than 22 weeks, and they had to be alive and free of any cancer at the time of diagnosis of the corresponding case. Controls were matched to cases on country and birth year of the case. In total 22185 cases and 220246 controls were included in the study.

Colorectal adenocarcinoma cases were identified using ICD-O-3 morphology codes in Denmark, Finland and Norway, and WHO/ HS/CANC/24.1 codes in Sweden. The following cancer subsites were considered: proximal colon (ICD-10/ICD-O-3 (Denmark, Finland, and Norway), C18.0-C18.5; and ICD-7 (Sweden), 153.0-153.1 and 153.4); distal colon (ICD-10/ICD-O-3, C18.6-C18.7; and ICD-7, 153.2-153.3); other colon (ICD-10/ICD-O-3, C18.8-C18.9; and ICD-7, 153.8-153.9); and rectum (ICD-10/ ICD-O-3, C19.9 and C20.9; and ICD-7, 154.0).

Statistical analysis. Odds ratios (ORs) with 95\% confidence intervals (95\% CIs) were derived from conditional logistic regression models. We examined the following reproductive variables: parity - number of births at the time of matching $(1,2,3$, and $\geqslant 4)$; age at first birth $(<20,20-29,30-39$, and $\geqslant 40$ years); age at last birth $(<20,20-29,30-39$, and $\geqslant 40$ years); time since first birth $(<10,10-19,20-29$, and $\geqslant 30$ years $)$; and time since last birth $(<10,10-19,20-29$, and $\geqslant 30$ years $)$. Stratified analyses were performed for ages $<50,50-59$, and $\geqslant 60$ years, which served as proxies for pre-, peri-, and postmenopausal status, respectively. We had limited information available on potential confounders.

We tested for differences between the countries by fitting logistic regression models with and without interaction terms between country of birth and the reproductive variables. The data were analysed using IBM SPSS Statistics 22 (IBM Corporation, Armonk, NY, USA) and Stata/IC 14.0 (StataCorp LP, College Station, TX, USA).

Ethical and legal considerations. This study was approved by the ethical committees in Norway and Sweden. In Denmark, the study was approved by the Data Protection Agency. In Finland, we obtained permission to use health registry data from the National Institute for Health and Welfare after approval by the data protection authority.

\section{RESULTS}

Characteristics of the study population are presented in Table 1. There were only minor differences between cases and controls. Table 2 shows colorectal adenocarcinoma by subsites and country. In total, $65 \%$ of cases had colon cancer (32\% in the proximal colon and $29 \%$ in the distal colon) and $35 \%$ had rectal cancer. Mean age at diagnosis was 57 years ( 57 years for colon cancer and 56 years for rectal cancer).

Table 3 displays ORs with 95\% CIs obtained from univariate analyses for colorectal adenocarcinoma according to reproductive factors. We found no evidence for associations between colorectal adenocarcinoma and parity, age at first and last birth, and time since first and last birth. For specific subsites (proximal and distal 
colon and rectum) the risk estimates also were close to unity. When the analyses were stratified on menopausal status (overall and for specific subsites), parity, and mother's year of birth $(<1950$ and $\geqslant 1950)$ (data not shown), no evidence for associations was found.

Table 1. Characteristics of the study population, Nordic countries, 1967-2013

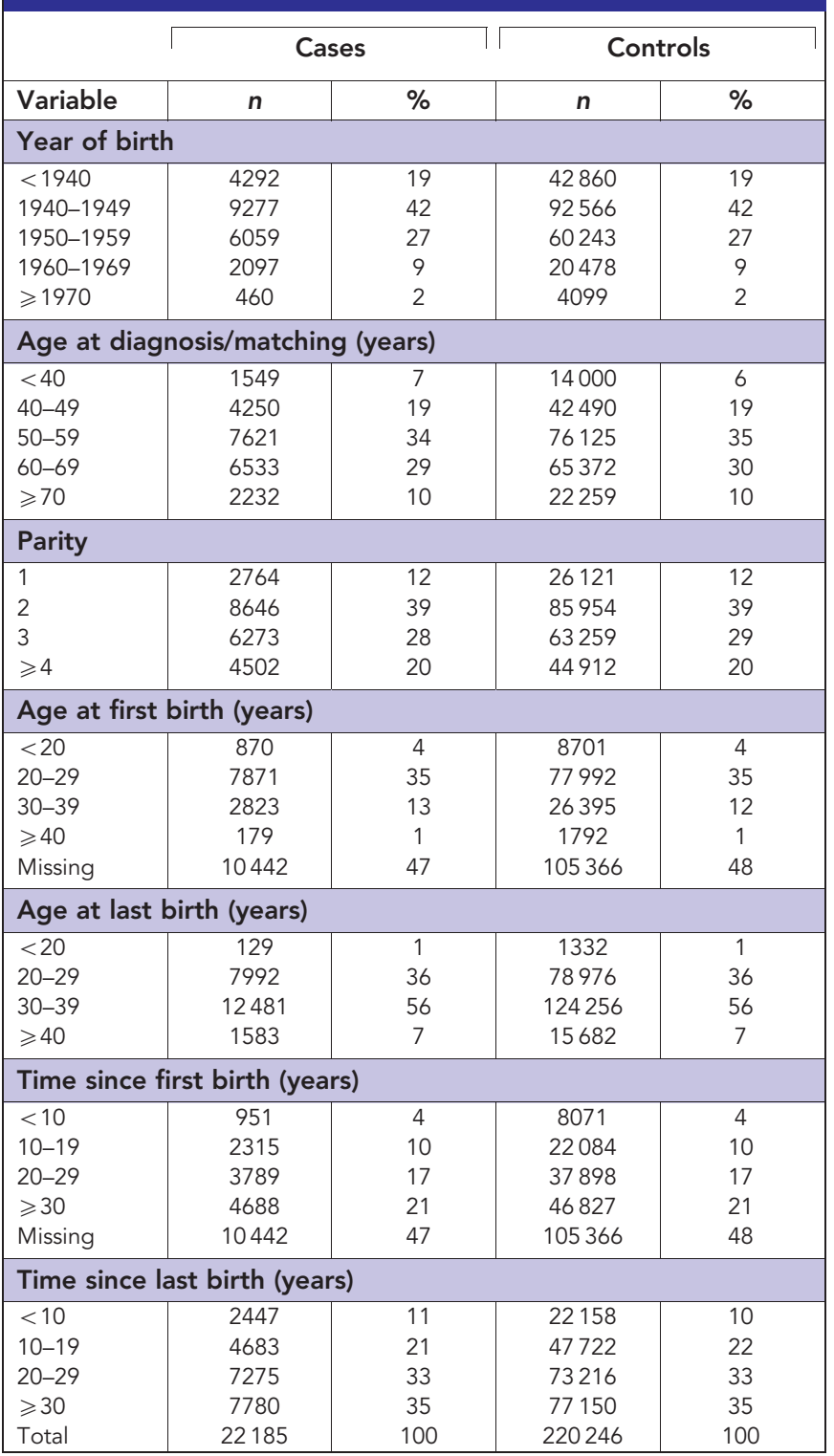

When we tested for potential differences between countries, no significantly improved fit emerged of models including interaction terms (data not shown).

\section{DISCUSSION}

In this large population-based Nordic study, no evidence for associations was observed between women's reproductive history and colorectal adenocarcinoma in parous women.

Studies to date regarding reproductive factors and colorectal cancer have been inconclusive. Our results showing no evidence for associations between reproductive history and colorectal adenocarcinoma, accord with some studies (Troisi et al, 1997; Tsilidis et al, 2010; Li et al, 2013), but not with others (Zervoudakis et al, 2011; Lu et al, 2014). A recent Swedish study, partly overlapping with the Swedish data in our study, found that higher parity was associated with increased risk of adenocarcinoma of the proximal colon, both when parous women were compared with non-parous women, and when analyses were restricted to parous women (Lu et al, 2014). An earlier Norwegian study, partly overlapping with the Norwegian data in our study, found associations between parity and subsites of the colorectum (Kravdal et al, 1993). However, in that study women with two or more children had a lower risk of cancer in the caecum or ascending colon, compared with non-parous women. A US study reported positive associations between age at first birth and colorectal cancer in postmenopausal women, whereas parity was inversely associated with risk in women with no history of HT use (Zervoudakis et al, 2011).

The women included in our study were relatively young as our study population was restricted to those being recorded with a prior birth in the national birth registries; $26 \%$ of cases were below age 50 , and median age at diagnosis was 57 years. As median age at diagnosis of patients with genetic syndromes is relatively low, that is, in the fifth decade (Stoffel et al, 2009), it is possible that women with hereditary forms of colorectal cancers were overrepresented in our study population, and that these may have a weaker association with reproductive factors than sporadic forms of the disease. However, when we stratified on mother's year of birth, no difference in the risk estimates was observed.

Among the strengths of our study were its large size, inclusion of all colorectal adenocarcinoma cases (more than 22000), with information on subsite, among women with at least one registered pregnancy in the four Nordic countries, and linkage of comprehensive databases with valid information and mandatory reporting (Teppo et al, 1994; Gissler et al, 1997; Barlow et al, 2009; Larsen et al, 2009; Gjerstorff, 2011). The study design using standardised data from registries also eliminated bias from participant selfselection and recall bias.

Table 2. Colorectal adenocarcinoma by subsite and country, Nordic countries, 1967-2013

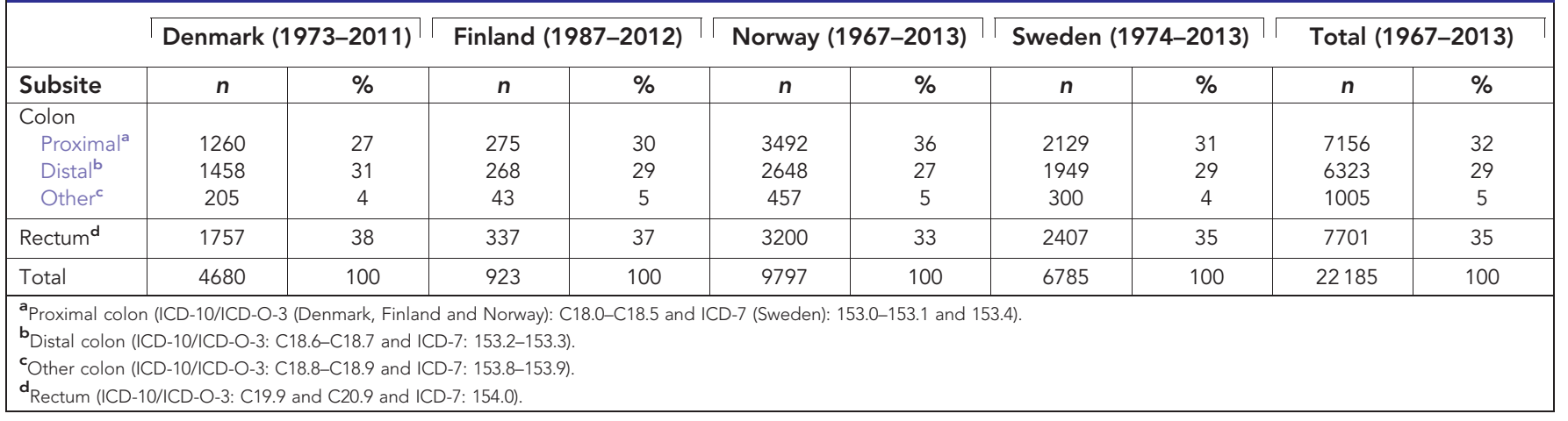


Table 3. ORs ${ }^{a}$ with $95 \% \mathrm{Cls}$ of colorectal adenocarcinoma according to reproductive factors and subsites, univariate analyses, Nordic countries, 1967-2013

\begin{tabular}{|c|c|c|c|c|c|c|c|c|}
\hline & \multicolumn{2}{|c|}{ Total } & \multicolumn{2}{|c|}{ Proximal colon } & \multicolumn{2}{|c|}{ Distal colon } & \multicolumn{2}{|c|}{ Rectum } \\
\hline & OR & $95 \% \mathrm{Cl}$ & OR & $95 \% \mathrm{Cl}$ & OR & $95 \% \mathrm{Cl}$ & OR & $95 \% \mathrm{Cl}$ \\
\hline \multicolumn{9}{|c|}{ Age at first birth (years) } \\
\hline$<20$ & 0.98 & $0.91-1.06$ & 1.01 & $0.88-1.16$ & 0.90 & $0.78-1.04$ & 1.04 & $0.92-1.18$ \\
\hline $20-29$ & 1.00 & Reference & 1.00 & Reference & 1.00 & Reference & 1.00 & Reference \\
\hline $30-39$ & 1.08 & $1.02-1.14$ & 0.99 & 0.89-1.09 & 1.15 & $1.04-1.27$ & 1.07 & $0.98-1.17$ \\
\hline$\geqslant 40$ & 1.03 & $0.84-1.26$ & 1.12 & $0.78-1.60$ & 1.03 & $0.72-1.48$ & 0.82 & $0.57-1.19$ \\
\hline \multicolumn{9}{|c|}{ Age at last birth (years) } \\
\hline$<20$ & 0.94 & $0.78-1.13$ & 0.90 & $0.64-1.25$ & 0.77 & $0.53-1.12$ & 1.12 & $0.84-1.50$ \\
\hline $20-29$ & 1.00 & $0.97-1.03$ & 0.99 & $1.05-1.11$ & 1.00 & $0.94-1.07$ & 0.97 & $0.92-1.03$ \\
\hline $30-39$ & 1.00 & Reference & 1.00 & Reference & 1.00 & Reference & 1.00 & Reference \\
\hline$\geqslant 40$ & 1.01 & $0.95-1.08$ & 0.97 & $0.87-1.11$ & 1.13 & $1.00-1.27$ & 0.98 & $0.87-1.09$ \\
\hline \multicolumn{9}{|l|}{ Parity } \\
\hline 1 & 1.04 & $1.00-1.09$ & 1.12 & $1.03-1.21$ & 0.92 & $0.85-1.01$ & 1.07 & $0.99-1.15$ \\
\hline 2 & 1.00 & Reference & 1.00 & Reference & 1.00 & Reference & 1.00 & Reference \\
\hline 3 & 0.99 & $0.96-1.02$ & 1.06 & $1.00-1.13$ & 0.98 & 0.92-1.04 & 0.94 & $0.89-1.00$ \\
\hline$\geqslant 4$ & 1.00 & $0.96-1.04$ & 1.01 & $0.94-1.09$ & 0.99 & $0.92-1.07$ & 0.98 & $0.92-1.05$ \\
\hline \multicolumn{9}{|c|}{ Time since first birth (years) } \\
\hline$<10$ & 1.00 & Reference & 1.00 & Reference & 1.00 & Reference & 1.00 & Reference \\
\hline 10-19 & 0.94 & $0.84-1.04$ & 0.84 & $0.69-1.02$ & 1.00 & $0.83-1.21$ & 0.94 & $0.79-1.12$ \\
\hline $20-29$ & 0.85 & $0.77-1.07$ & 0.78 & $0.62-0.98$ & 0.86 & 0.69-1.06 & 0.97 & $0.79-1.18$ \\
\hline$\geqslant 30$ & 0.86 & $0.75-0.98$ & 0.85 & $0.66-1.09$ & 0.76 & $0.60-0.96$ & 1.00 & $0.80-1.24$ \\
\hline \multicolumn{9}{|c|}{ Time since last birth (years) } \\
\hline$<10$ & 1.00 & Reference & 1.00 & Reference & 1.00 & Reference & 1.00 & Reference \\
\hline 10-19 & 0.90 & $0.84-0.97$ & 0.89 & $0.77-1.02$ & 0.88 & $0.78-1.00$ & 0.92 & $0.82-1.04$ \\
\hline $20-29$ & 0.92 & $0.84-1.00$ & 0.88 & $0.75-1.04$ & 0.85 & $0.73-0.98$ & 1.00 & $0.87-1.15$ \\
\hline$\geqslant 30$ & 0.95 & 0.86-1.04 & 0.98 & $0.82-1.17$ & 0.84 & $0.71-1.00$ & 1.02 & $0.87-1.19$ \\
\hline
\end{tabular}

A study weakness was lack of information on possible confounders, such as use of exogenous hormones (OCs and HT), age at menarche and menopause, obesity, smoking, physical activity, and aspirin/NSAID use. It is possible that these factors act in opposite directions, and thus contribute to an overall null effect. However, in the Swedish study on reproductive history and colorectal adenocarcinoma, adjustment for diabetes, obesity, diagnoses associated with tobacco smoking and alcohol overconsumption, as well as bilateral oophorectomy (representing HT) did not change risk estimates materially (Lu et al, 2014).

A case-control design was chosen due to the strict confidentiality and data protection legislation in the Nordic countries covering access to data on the entire population and data exchange between countries. Use of 10 controls per case approximated the efficiency provided by a cohort design.

No data were missing for parity, age at last birth, and time since last birth, whereas about $48 \%$ of women lacked data on age at first birth and time since first birth, mostly due to the relatively recent establishment of the birth registries. In Finland, where the birth registry was established in 1987 , more than $63 \%$ of women had missing data on age at first birth. The relatively young age of the Finnish cohort also strongly limits the number of cancer cases.

In conclusion, we found no evidence for associations between women's reproductive history (parity, age at first and last birth, and time since first and last birth) and colorectal adenocarcinoma in parous women.

\section{ACKNOWLEDGEMENTS}

This study was supported by the Nordic Cancer Union, Program for Clinical Research Infrastructure (PROCRIN) established by the
Lundbeck Foundation and the Novo Nordisk Foundation, Danish Cancer Society, Svenska Sällskapet för Medicinsk Forskning (SSMF), Svenska Läkarsällskapet, and the U.S. National Cancer Institute, National Institutes of Health, Department of Health and Human Services.

\section{CONFLICT OF INTEREST}

The authors declare no conflict of interest.

\section{REFERENCES}

Barlow L, Westergren K, Holmberg L, Talback M (2009) The completeness of the Swedish Cancer Register: a sample survey for year 1998. Acta Oncol 48(1): 27-33.

Bayerdorffer E, Mannes GA, Ochsenkuhn T, Dirschedl P, Wiebecke B, Paumgartner G (1995) Unconjugated secondary bile acids in the serum of patients with colorectal adenomas. Gut 36(2): 268-273.

Bosetti C, Bravi F, Negri E, La Vecchia C (2009) Oral contraceptives and colorectal cancer risk: a systematic review and meta-analysis. Hum Reprod Update 15(5): 489-498.

Bouvard V, Loomis D, Guyton KZ, Grosse Y, Ghissassi FE, Benbrahim-Tallaa L, Guha N, Mattock H, Straif K (2015) Carcinogenicity of consumption of red and processed meat. Lancet Oncol 16(16): 1599-1600.

Boyle T, Keegel T, Bull F, Heyworth J, Fritschi L (2012) Physical activity and risks of proximal and distal colon cancers: a systematic review and meta-analysis. J Natl Cancer Inst 104(20): 1548-1561.

Brenner H, Kloor M, Pox CP (2014) Colorectal cancer. Lancet 383(9927): 1490-1502.

Campagnoli C, Abba C, Ambroggio S, Peris C (2003) Differential effects of progestins on the circulating IGF-I system. Maturitas 46(Suppl 1): S39-S44. 
Campbell-Thompson M, Lynch IJ, Bhardwaj B (2001) Expression of estrogen receptor (ER) subtypes and ERbeta isoforms in colon cancer. Cancer Res 61(2): 632-640.

Chlebowski RT, Wactawski-Wende J, Ritenbaugh C, Hubbell FA, Ascensao J, Rodabough RJ, Rosenberg CA, Taylor VM, Harris R, Chen C, Adams-Campbell LL, White E (2004) Estrogen plus progestin and colorectal cancer in postmenopausal women. $N$ Engl J Med 350(10): 991-1004.

Drew DA, Cao Y, Chan AT (2016) Aspirin and colorectal cancer: the promise of precision chemoprevention. Nat Rev Cancer 16(3): 173-186.

Elmunzer BJ, Hayward RA, Schoenfeld PS, Saini SD, Deshpande A, Waljee AK (2012) Effect of flexible sigmoidoscopy-based screening on incidence and mortality of colorectal cancer: a systematic review and meta-analysis of randomized controlled trials. PLoS Med 9(12): e1001352.

Engholm G, Ferlay J, Christensen N, Bray F, Gjerstorff ML, Klint A, Kotlum JE, Olafsdottir E, Pukkala E, Storm HH (2010) NORDCAN a Nordic tool for cancer information, planning, quality control and research. Acta Oncol 49(5): 725-736.

Fedirko V, Tramacere I, Bagnardi V, Rota M, Scotti L, Islami F, Negri E, Straif K, Romieu I, La Vecchia C, Boffetta P, Jenab M (2011) Alcohol drinking and colorectal cancer risk: an overall and dose-response metaanalysis of published studies. Ann Oncol 22(9): 1958-1972.

Friis S, Riis AH, Erichsen R, Baron JA, Sorensen HT (2015) Low-dose aspirin or nonsteroidal anti-inflammatory drug use and colorectal cancer risk: a population-based, case-control study. Ann Intern Med 163(5): 347-355.

Gissler M, Louhiala P, Hemminki E (1997) Nordic Medical Birth Registers in epidemiological research. Eur J Epidemiol 13(2): 169-175.

Gjerstorff ML (2011) The Danish Cancer Registry. Scand J Public Health 39(7 Suppl): 42-45.

Grodstein F, Newcomb PA, Stampfer MJ (1999) Postmenopausal hormone therapy and the risk of colorectal cancer: a review and meta-analysis. Am J Med 106(5): 574-582.

Iacopetta B (2002) Are there two sides to colorectal cancer? Int J Cancer 101(5): 403-408.

Jess T, Rungoe C, Peyrin-Biroulet L (2012) Risk of colorectal cancer in patients with ulcerative colitis: a meta-analysis of population-based cohort studies. Clin Gastroenterol Hepatol 10(6): 639-645.

Kravdal O, Glattre E, Kvale G, Tretli S (1993) A sub-site-specific analysis of the relationship between colorectal cancer and parity in complete male and female Norwegian birth cohorts. Int J Cancer 53(1): 56-61.

Larsen IK, Smastuen M, Johannesen TB, Langmark F, Parkin DM, Bray F, Moller B (2009) Data quality at the Cancer Registry of Norway: an overview of comparability, completeness, validity and timeliness. Eur J Cancer 45(7): 1218-1231.

Larsson SC, Orsini N, Wolk A (2005) Diabetes mellitus and risk of colorectal cancer: a meta-analysis. J Natl Cancer Inst 97(22): 1679-1687.

Lee GH, Malietzis G, Askari A, Bernardo D, Al-Hassi HO, Clark SK (2015) Is right-sided colon cancer different to left-sided colorectal cancer? - a systematic review. Eur J Surg Oncol 41(3): 300-308.

Li CY, Song B, Wang YY, Meng H, Guo SB, Liu LN, Lv HC, Wu QJ (2013) Age at menarche and risk of colorectal cancer: a meta-analysis. PLoS One 8(6): e65645.

Liang PS, Chen TY, Giovannucci E (2009) Cigarette smoking and colorectal cancer incidence and mortality: systematic review and meta-analysis. Int J Cancer 124(10): 2406-2415.
Lin KJ, Cheung WY, Lai JY, Giovannucci EL (2012) The effect of estrogen vs. combined estrogen-progestogen therapy on the risk of colorectal cancer. Int J Cancer 130(2): 419-430.

Lu Y, Oddsberg J, Martling A, Lagergren J (2014) Reproductive history and risk of colorectal adenocarcinoma. Epidemiology 25(4): 595-604.

Ma Y, Yang Y, Wang F, Zhang P, Shi C, Zou Y, Qin H (2013) Obesity and risk of colorectal cancer: a systematic review of prospective studies. PLoS One 8(1): e53916.

McMichael AJ, Potter JD (1980) Reproduction, endogenous and exogenous sex hormones, and colon cancer: a review and hypothesis. J Natl Cancer Inst 65(6): 1201-1207.

Renehan AG, Zwahlen M, Minder C, O’Dwyer ST, Shalet SM, Egger M (2004) Insulin-like growth factor (IGF)-I, IGF binding protein-3, and cancer risk: systematic review and meta-regression analysis. Lancet 363(9418): 1346-1353.

Stoffel E, Mukherjee B, Raymond VM, Tayob N, Kastrinos F, Sparr J, Wang F, Bandipalliam P, Syngal S, Gruber SB (2009) Calculation of risk of colorectal and endometrial cancer among patients with Lynch syndrome. Gastroenterology 137(5): 1621-1627.

Taylor DP, Burt RW, Williams MS, Haug PJ, Cannon-Albright LA (2010) Population-based family history-specific risks for colorectal cancer: a constellation approach. Gastroenterology 138(3): 877-885.

Teppo L, Pukkala E, Lehtonen M (1994) Data quality and quality control of a population-based cancer registry. Experience in Finland. Acta Oncol 33(4): 365-369.

Troisi R, Schairer C, Chow WH, Schatzkin A, Brinton LA, Fraumeni JF Jr (1997) Reproductive factors, oral contraceptive use, and risk of colorectal cancer. Epidemiology 8(1): 75-79.

Tsilidis KK, Allen NE, Key TJ, Bakken K, Lund E, Berrino F, Fournier A, Olsen A, Tjonneland A, Overvad K, Boutron-Ruault MC, Clavel-Chapelon F, Byrnes G, Chajes V, Rinaldi S, Chang-Claude J, Kaaks R, Bergmann M, Boeing H, Koumantaki Y, Stasinopoulou G, Trichopoulou A, Palli D, Tagliabue G, Panico S, Tumino R, Vineis P, Bueno-de-Mesquita HB, van Duijnhoven FJ, van Gils $\mathrm{CH}$, Peeters $\mathrm{PH}$, Rodriguez L, Gonzalez CA, Sanchez MJ, Chirlaque MD, Barricarte A, Dorronsoro M, Borgquist S, Manjer J, van GB, Hallmans G, Rodwell SA, Khaw KT, Norat T, Romaguera D, Riboli E (2010) Oral contraceptives, reproductive history and risk of colorectal cancer in the European Prospective Investigation into Cancer and Nutrition. Br J Cancer 103(11): $1755-1759$.

Ullman TA, Itzkowitz SH (2011) Intestinal inflammation and cancer. Gastroenterology 140(6): 1807-1816.

Zervoudakis A, Strickler HD, Park Y, Xue X, Hollenbeck A, Schatzkin A, Gunter MJ (2011) Reproductive history and risk of colorectal cancer in postmenopausal women. J Natl Cancer Inst 103(10): 826-834.

Zhao C, Dahlman-Wright K, Gustafsson JA (2010) Estrogen signaling via estrogen receptor \{beta\}. J Biol Chem 285(51): 39575-39579.

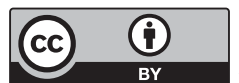

This work is licensed under the Creative Commons Attribution 4.0 International License. To view a copy of this license, visit http://creativecommons.org/licenses/by/4.0/ 